\title{
1. Challenges and opportunities of the refugee movement of 2015 in Europe
}

What happened in Germany and other European countries in autumn 2015 was more than a giant 'wave of refugees'. For a certain time the territorial boundaries of many member states of the European Union (EU) had been torn down. One and a half million people looking for protection and asylum entered the EU irregularly. In many countries, civil society received the refugees cordially and helped to cope with their basic needs. In September and October 2015 politicians and state agencies showed up as being taken by surprise and having no coherent answer. The heartfelt welcoming ceremonies at Munich Central Station and other points of arrival were a kind of spontaneous silent revolution and, at the same time, an outcome of long-lasting activities of support and reception of refugees that civil society and its organizations had developed for decades. Hundreds of thousands of activists had been distributing clothes, preparing housing, organizing language courses, sports and cultural activities and helping refugees with dealing with the authorities. They gave a clear message to refugees: you are safe now! You are welcome and you have arrived safely. There had been no comparable public commitment for decades, perhaps since the social movements for peace and for ecological affairs in the early 1980s. The issue of the refugees dominated print media, television and the internet for months.

This hearty welcome of the refugees by civil society was above all a spontaneous gesture of humanity and solidarity. However, it also made clear that neither politicians nor authorities had been prepared to deal with the number of people looking for protection. Confronted with this tremendous challenge - reaching from providing sufficient accommodation to organizing orderly asylum procedures - and the spontaneous willingness to help of great parts of civil society in Austria, Germany, Greece, Hungary, Sweden and other countries, the political system also sprang into action. Angela Merkel had courageously declared at the Federal Press Conference as early as 31 August 2015: 'We have managed so much - we will manage this!' Hundreds of mayors and thousands of public 
institutions energetically worked in that sense. A new image of Austria, Germany and other countries as societies of solidarity went around the world swiftly. This certainly also raised hopes for a successful arrival amongst many refugees.

Nevertheless, the problems connected to the movement of refugees became obvious as early as October and November 2015. The optimistic statement 'We will manage this!' was more and more superseded by the sceptical question 'Will we manage this?' This was also highlighted by the political discord amongst the member states of the EU. Politicians from Hungary and the Czech Republic blamed the German chancellor for the endless influx of refugees. According to these statements, her policy of 'We will manage this!' had directly encouraged the refugees waiting in Syria, Turkey or Greece to come to Western Europe. The cry of German cities and municipalities grew louder that they were no longer able to guarantee a proper reception and treatment of the asylum seekers. Violent clashes between different groups began to occur in refugee accommodations. Right-wing populist parties and organizations saw that their time had come and started to play with the fire of prejudices and fears, some of them even went on to physical collective attacks against refugees.

How Europe and the international community will deal with the challenges of refugees and their protection will affect the future of the people directly concerned but also in the longer term the self-conception of the EU as a political project. It will define for the twenty-first century, if and how global society and its nation-states stick to the humanitarian commitments they defined during the twentieth century. Especially in the German case, the massive welcoming and the clear signal to the refugees that they had arrived safely in Germany also opened a historic window for society to arrive at a more sustainable concept of itself. Many people, especially younger persons and those with migration roots, declared that this was the first time they felt proud of the country they lived in. Faced with criticism from politicians from Germany and other European countries, chancellor Merkel declared in mid-September 2015: 'When we should be forced to apologize right now, for showing a friendly face when confronted with an emergency situation, then this is no more my country.'

After the Second World War in Germany, the "Mantra of the defensive refusal of knowledge-reception "Germany is no country of immigration"" (Bade 2002, p. 1) had been predominant for half a century. Also in many other EU member countries (such as Austria, Denmark, France and the Netherlands) there were engaged debates and conflicts of defining oneself as a multicultural or immigration society. In Germany, since the beginning of the twenty-first century a new cognitive framing had progressively gained ground that perceived the country as a pluri-cultural society of 
immigration. The 'autumn of welcoming refugees' of 2015 let show up this new self-perception and, at the same time, to a certain extent was a release for many people living there. Against the background of the Second World War almost two-thirds of all families living in Germany had some experiences of forced migration; additionally, one-fifth of all persons living in Germany had a migration history based mainly on the 'Guestworker' influx since the 1950s.

The new self-awareness and self-description as a country of immigration with diverse cultural currents and migratory movements, and the deep historic experiences of forced migration, opened a 'window of opportunity'. The needs and ways for arrival were reconsidered - arrival not only for the refugees but also for many other groups living in this country. Since looking back only one or two generations nearly all families in Germany have experiences with expulsion, flight, migration and - successful, denied or missed - arrival. By this, the new immigration of refugees in 2015 also facilitated a kind of catharsis for those already living in Germany to work their own (family) experiences, because after the devastations of the Nazi regime there was not only an 'inability to mourn' (Mitscherlich and Mitscherlich 1967), but a general climate of historical and biographical suppression and oblivion had been dominant.

More than 1.5 million persons came to the EU in 2015 looking for protection, ${ }^{1}$ two-thirds of them to Germany, and the way in which hundreds of thousands of helpful people welcomed them in many European countries fundamentally moved and shook the countries' self-perception and perception by others. The political project of the EU is shaped by the way its member states managed and will handle the so-called refugee crisis. ${ }^{2}$ Therefore, the opportunities and chances for developing refugee protection and possibilities of arrival in Germany and other countries are

1 As many border crossings by refugees and other migrants were neither in Germany nor in other countries of the EU exactly recorded, the numbers given in publications vary largely. In Germany the Federal Office for Migration and Refugees (Bundesamt für Migration und Flüchtlinge: BAMF) registered 1,091,894 asylum seekers in its EASY-system (Erstverteilung der Asylbegehrenden [Initial Distribution of Asylum Seekers; EASY) for the registration and initial distribution of asylum seekers. In total, in 2015 some 1.5 million migrants entered the EU irregularly; some 1.3 million applied for asylum, see: Eurostat 22-02-2017: Asylum and first time asylum applicants (rounded) [migr_asyappctza]; see also https:/www.ceps.eu/ publications/rethinking-asylum-distribution-eu-shall-we-start-facts.

2 The term 'refugee crisis' will be handled in simple quotation marks or addressed as 'so-called refugee crisis'. Because, as UN Secretary General Ban Ki Moon characterized it, 'this is not a crisis of numbers; it is a crisis of solidarity' (see UN Press Release of 15 April 2016 'Refugee Crisis about Solidarity, Not Just Numbers'; http://www.un.org/press/en/2016/ sgsm17670.doc.htm). Fassin (2016) also argues: 'The so-called European refugee crisis is a moral issue before it is a demographic one.' For a critical discussion of the term and concept of 'the refugee' see, for example, Malkki (1995). 
deeply entangled with the challenges of coping with international forced migration flows. After all, the EU could be more unified or could crumble into different parts. Thus the social response to the 'refugee crisis' of 2015 will change the face of Europe and its member states more than the management of the financial crisis of 2008. How civil society, state policies and polities, non-governmental organizations (NGOs) and the public sphere negotiate the treatment of the immigrated refugees will also redefine the society's self-conception: are the standards of refugee protection an integral element of the European project or just a plaything for political pressure groups? Can the EU member states and the EU as a whole find a way out of organized non-responsibility? ${ }^{3}$ How can not only physical, but also mental and socio-cultural arrival of the refugees as well as of other social groups be achieved?

The aim of this book is to convey a deeper understanding for these basic changes and the challenges as well as key choices linked to them. Exactly because much more is at stake than short-term crisis management, more far-reaching sociological reflections are required. The book is based on different sources. The broader topics of refugee protection, mixed migration flows and the Common European Asylum System (CEAS) were studied in the context of working as deputy president of the Expert Council of German Foundations on Integration and Migration/ Berlin (Sachverständigenrat deutscher Stiftungen für Migration und Integration, SVR). Empirical field research was done in the context of a teaching-research project with students in five EU member states at the Mediterranean Sea (Cyprus, Greece, Italy, Malta and Spain) where the networks of organizations dedicated to deal with refugees were analysed (see Gansbergen et al. 2016; Mratschkowski 2017). Secondary data analysis of national and European sources and scientific publications was done from 2015 to 2017. My stay in Mexico from 2015 to 2017 even increased sensitivity for the complex situation of countries that are countries of emigration, of immigration and of transit migration at the same time; and it led to understanding the nexus between voluntary and forced migration, organized violence and the lack of local or regional development.

This book is pervaded by three basic ideas. First, the dynamics of the refugee events of 2015 reflect the degree of globalization and transnationalization of social relations. Most people perceive their life through the framework of national 'container societies'. Similar to the concentric layers of an onion or the Russian Matryoshka dolls people normally imagine their lives embedded in local, regional and national frameworks.

3 The concept of organized non-responsibility will be dealt with in detail in Chapter 3 , section 3 . 
According to the concept of 'national container societies' and of 'methodological nationalism' (Wimmer and Glick Schiller 2002) the most important social spaces of reference are nation-states. Although there exist some supranational associations like the EU or global institutions like the United Nations, these are considered not important in terms of power and relevance for life destiny. Therefore, according to this perspective, the most important point of reference for peoples' own self-definition and formulation of interests remains the state-pacified national society - this is considered the framework for collective identities and for the perception of differentiated living conditions and life chances. The dominant framing of peoples' lives by national societies is also reflected in how legitimation for politicians is created. The stability of the principle of 'national containers' is precisely proven by the tendencies towards a (re-)nationalization of politics and society across the EU during the last years, especially since the 'refugee crisis' of 2015. Right-wing populist, nationalist and xenophobic political forces base themselves on this view of the world.

The cognitive model of national 'container societies' is, as demonstrated elsewhere (Pries 2008), by no means completely inappropriate. In fact, it can explain a wide range of phenomena. But it is not sufficient to explain societies in the twenty-first century and has to be complemented. Globalization, glocalization and transnationalization - and as far as flight and asylum are concerned also Europeanization - are deep-going tendencies of change that are gradually 'puncturing' the national containers. The term glocalization describes the increasing interdependence between global problems and developments and specific local and regional social circumstances. This concept is as important as that of transnationalization to understand the recent movement of refugees. The term transnationalization describes the increase of social relationships, networks and social spaces, which transcend a number of nation-states.

The local armed conflicts in Syria can only be deciphered in the framework of such a multilevel perspective. Here global climate changes, resource-led interests and fundamentalist mobilizations are interwoven with regional power structures, transnational relations and local circumstances. In Syria the global is becoming local and the local is becoming global (as in by the spreading threat of the Islamic State). At the same time transnational social relations are becoming more and more important, such as the social, ethno-cultural and political networks between different groups of Kurds in Turkey, Iraq and Syria or the transnational family ties between places in Syria, the refugee camps in Lebanon and European cities, where family members with a recognized refugee status are living. In addition, the local actions of refugees and of civil society groups of refugee support can only be understood when the global, transnational 
and regional circumstances are taken into account. Civil society, authorities, politicians and media all act in the framework of cognitive multilevel interpretative patterns and often in the framework of their own transnational relationships. They know that the violent conflicts in Syria will not end soon. That is also the reason why the refugees have set out. Forced migrants also use transnational 'mental maps' that cover the different national conditions of refugee protection and that include already existing transnational social relationships to relatives and acquaintances.

The movement of refugees can only be understood against the backdrop of a set of problems, which can be characterized as a new transnational social question. Contrary to the social question of the industrializing societies of the nineteenth century, the new social question is not primarily one of poverty, hunger, child labour, of protection of health and occupational safety - even if millions of people are still directly affected by these problems. Today's new social question is characterized by a vicious circle of (1) lack of social development; (2) armed conflicts and organized violence; and (3) forced migration. This new social question includes the absence of even a minimum level of public security and predictability of peoples' lives. Legal and regular income opportunities as well as any belief in state authorities and the possibility to mould one's own life are missing. The new social question is transnational because its roots and its possible solutions are and have to be transgressing state boundaries. If there is no solution for the new transnational social question on the regional level, where it is most virulent, then the people affected by it will set off to find a better life somewhere else. The vicious circles of lack of development, organized violence and forced migration are at the very heart of the new transnational social question.

Taking this as the background and crucial causes of the 'refugee crisis' of 2015 in Europe, the second main thesis of this book is: since the 1990s a European refugee regime has been being developed, but its (nice) provisions for refugee protection almost collapsed in face of the organized non-responsibility of EU member states. The overall conclusion is that the EU has achieved a substantial improvement of the norms of protection for refugees and an 'upward harmonization', an upgrading in comparison to the laws of the individual member countries as far as the legal and regulatory framework is concerned. European networks like the European Migration Network (EMN) and agencies like the European Asylum Support Office (EASO) were established some years ago and have become operational since that time. Thus, steps were taken towards the professionalization and a common normative orientation of the EU actors concerned with questions of asylum and refuge. However, most politicians and an important proportion of civil society - apart from those 
professionals who are directly in charge and varying in its public weight according to member states and specific situations - still adhere to national patterns on the cognitive level of problem perception where challenges and possible solutions are concerned. Political parties such as Front National in France, the Party for Freedom in the Netherlands, the Freedom Party of Austria or the Alternative for Germany reflect these quite high shares of national civil societies that explicitly reject the already installed level of normative refugee protection at EU level.

The disparate treatment of refugee admission, recognition of refugees, designation of safe countries of origin and the absence of burden sharing show that the EU is miles away from any real institutionalization of a European protection of refugees. On the formal level, the CEAS had been passed in 2013. It contains more far-reaching provisions for the protection of refugees than comparable regulations of the individual member states. Nevertheless - and this has been highlighted by the so-called refugee crisis - there is a huge gap between the normative structure, the talk of the CEAS, and the action of the relevant actors on the local, national and European levels. How can we explain this apparent contradiction between the rather differentiated normative framework for the protection of refugees and the prevailing organized non-responsibility?

The tension between talk and action and the differing degrees of implementation of the CEAS can be examined using the theory of sociological neo-institutionalism. ${ }^{4}$ According to this approach we have to assume that decision making in questions related to asylum and refugees involves many organizations as collective (interest groups, NGOs) or corporate actors (states, companies, and so on) on all levels (local, national, supranational and transnational). These collective and corporate actors pursue diverging targets and follow different strategies. On the one hand, these organizations follow their own, more or less rationally calculated interests, while on the other hand they act according to the perceived expectations of legitimacy of their organizational field (being the context for all collective and corporative actors that is relevant for their actions and communication). There is an organizational field in which the relevant expectations of legitimacy are determined by social institutions as stable norms and programmes of perception and action.

Institutions exercise influence either by force (in the form of regulatory instructions or government requirements), by norms (in the form

4 The basic texts are Meyer and Rowan (1977); DiMaggio and Powell (1983); Scott (1991) and (2001). A good overview and discussion is provided in Brinton and Nee (2001) and by Powell (2008); Meyer and Jepperson (2000) underline the importance of New Institutionalism for the social sciences. 
of internalized and shared guidelines and ideas) or by cultural-cognitive framings (in the form of interpretative patterns and expectations that are taken for granted). Some scientists adhering to the school of neoinstitutionalism assume that strategies of legitimization on the organizational field (talk) can be disconnected from actual behaviour (action) only for a certain time and to a certain degree. Others argue that collective or corporative actors can permanently play false and keep up an opportunistic facade to hide completely different structures and practices (Oliver 1991; Scott 1991).

Irrespective of whether or not a permanent disconnection between talk and action is possible, a lasting stabilization of social institutions is according to the theory of neo-institutionalism only possible when its regulative, normative and cognitive pillars stand firmly and actually organize the organizational field as the relevant environment of the actors involved. ${ }^{5}$ The Europeanization of refugee protection and the institutionalization of the CEAS means that all relevant corporative (local, national and European state and official agencies such as the police; agencies deciding on the legal status of refugees; agencies for monitoring and consultation such as EASO; international governmental organizations such as the United Nations High Commissioner for Refugees, UNHCR) and collective actors (local, national and European NGOs related to refugees such as refugee councils, Pro Asyl, European Council on Refugees and Exiles) have to see each other as parts of an EU-wide organizational field. These collective and corporate actors orient their strategies and structures according to the (perceived or supposed) expectations of legitimacy linked to this field.

As will be highlighted below, the legal-regulatory framework of the CEAS is quite sound in spite of many contradictions. But the normative and cognitive pillars of European refugee protection are still very fragile. This fact is highlighted by the organized non-responsibility within and between the EU member states. The EU has - as will be shown in Chapter 4 , section 4.1 - only begun to develop the normative foundations for a common protection of refugees in the sense of a professionalization and normative orientation of those politicians and administrators responsible for questions related to asylum and refugees. The cognitive pillar of common European mental-perceptive patterns has been further

\footnotetext{
5 The regulative pillar consists of formalized rules and regulations, for example laws or regulations that can be enforced by legal sanctions. The normative pillar consists of social obligations founded in morale and guidelines for action founded in professional ethics. The cognitive pillar comprises of the cognitive patterns of social reality that are taken for granted and part of the cultural heritage (see Scott 2001, pp. $33 \mathrm{ff}$.).
} 
strengthened by the civic activities of the refugee movement, but most politicians and broad sectors of civil society are still miles away from a European conception and framing of the challenges and possible solutions in connection with refugees. To sum it up, the institutionalization of the CEAS had been too underdeveloped and too fragile to cope with the 'refugee crisis' of 2015 on a European level.

The third main idea of this book is that the networks of refugee- and asylum-oriented organizations and elements of a related transnational social movement compensated, to a certain extent, the lack of serious action of refugee protection by state authorities in Europe. Fully in line with the transnational character of the new social question during the 'refugee crisis' of 2015 we did not only witness the spatial movement of numerous individuals, such as from Syria via the Balkan Route to Austria, Germany or Sweden. These spatial movements of individuals and small family groups were embedded in broader transnational activity structures of communication and support, which rally around refugee protection and the corresponding norms and stipulations of international, humanitarian, European and national law. Social movements can be understood as 'social entities made up of interconnected persons, groups and organisations, that express protest by collective actions in order to change social or political circumstances or to counteract ongoing changes' (Rucht and Neidhardt 2001, p. 540).

In this sense, we probably cannot speak of an already existing transnational social movement of refugee protection but can witness many elements of such an emerging movement. The primary aim of most refugees was and is certainly to be safe, to claim for minimum protection and to escape certain political conditions - not to change them (this aim of changing or conserving things is considered a characteristic of classic social movements). The classical image of a refugee is that of a passive sufferer, beaten out by external conditions, who has no other choice but to flee. At first glance this is directly contradictory to the definition of a social movement cited above, as its aim is primarily to change (or preserve) existing conditions. Yet, as will be shown later (Chapter 2.3), refugees - although being victims of acts of nature beyond control - have to be conceptualized not as passive objects but as actors who in general collectively stand up for their own interests in spite of their plight.

An extended sociological definition of refugees as forced migrants will also include people who are internally displaced persons (IDPs) living in their own country and people who have to flee their country for other reasons (such as environmental refugees). Such an extended definition also embraces those who had to flee from their own country due to direct persecution and an immediate threat to their lives, but who have not (yet) 
been formally recognized as refugees or entitled to asylum. It is essential to view refugees not primarily as objects and victims but as actors who take decisions and move always in the framework of broader social relations. They did not choose the conditions of living that forced them to flee but they shape their course of life themselves.

Broadening our view and taking into account the social relations and social spaces of the refugees during their flight and after their arrival, NGOs and national and international governmental organizations advancing the rights and interests of refugees have to be included. They are part of what we shall call the civic-social movement for the protection of refugees and asylum or - abbreviated - the refugee movement. Charles Tilly (2004, pp. 3 f.) defined social movements as permanent and public efforts and collective demands directed towards certain authorities and agencies. In this sense, the transnational movement of refugees can be seen as a form of emerging new transnational activism (Tarrow 2005). Individual and collective actors are integrated into this movement of refugees as a transnational social movement, who do not form a self-contained and coherent organized unit, but resemble a loose cooperation network.

Collective demands for legal paths of entry for refugees, for example, or for fair asylum procedures and humane accommodation are directed towards national authorities such as politicians and agencies concerned with migration, towards European institutions like the European Commission or EASO, to international bodies like the International Organization for Migration (IOM) and UNHCR. This transnational civic-social movement for the protection of refugees and asylum distinguishes itself by an eventrelated potential for mobilization and an effective capacity to exercise pressure in the public sphere. It is capable of influencing the expectations towards the legitimacy of politicians, media and organizations dealing with flight and asylum by affecting the cognitive framing of refugee and asylum issues in public discourse, as well as influencing normative action strategies. Finally, this movement aims at the transformation of individual and social conditions by stressing the transnational character of the causes of flight. We cannot debate the future of refugee movements and the protection of refugees without considering in an integrated approach the political system, refugees and their social networks and the organizations dealing with refugees.

The structure of this book is as follows. A reconstruction of the events of autumn 2015 (Chapter 2) will show that these can only be understood and explained as a complex network of rational decisions, spontaneous acts of desperation, courageous actions and tactical behaviour by individual and collective actors: refugees, their non-profit or for-profit assistants, state bodies, NGOs and politicians on the local, national and European levels. 
The scientific analysis of these processes will be facilitated by some sociological rules such as the 'unanticipated consequences of purposive social action' (Merton 1936) or the Thomas theorem, according to which, 'if men define situations as real, they are real in their consequences' (Thomas and Thomas 1928, p. 572).

Then the civic engagement during 2015 will be analysed that preceded the activities of state bodies and politicians and that generated a certain pressure on the authorities to set themselves in motion (Chapter 3). Who were the people and organizations that have been doing so much for the reception and accommodation of refugees since the late summer of 2015 ? Who were their predecessors in Europe? Who got active and for what reasons? The answers to these questions will help to judge how sustainable their engagement will be. Chapter 4 deals with the reaction of important groups of political actors and administrative authorities. Concerning asylum and refugee politics, their activities have been characterized by an organized non-responsibility by which tasks and duties are pushed to other actors that, at the same time, are blamed for what they are doing. This confusion enabled the corresponding actors to move the responsibilities back and forth between the local, regional or district, federal and EU levels and thus to disguise their own inactivity by pointing to the shortcomings of others - at the expense of the directly affected refugees. As will be shown, due to power relations in the fields of legitimacy there had not been many possibilities to breach this wall of reciprocal paralysis until refugees acted in social networks and civil society organized collective action.

The often-cited 'causes of refuge' will be analysed in Chapter 5. It is argued that the approach on the development-migration-nexus has to be broadened to analyse the vicious circles of lack of development, organized violence and forced migration. This is considered to be the new transnational social question of the twenty-first century. We will treat especially the role of organized violence in its different forms. We also will present empirical evidence from two broader regions, where its entanglement with lack of development and forced migration could be observed, that is: Central-North America and sub-Saharan-North Africa-Middle East-Europe.

Chapter 6 deals with the great opportunities for European societies not only to let refugees arrive, but to arrive at oneself in the sense of a more adequate self-perception and arrival at one's inner world and true self. Here we can distinguish three levels. First, the 'refugee crisis' of 2015 allows us to use the experiences of persecution, displacement and flight during and after the Nazi regime for the 'cognitive framing' of the present situation. Second, it becomes possible to critically reprocess the treatment of the 'guest-workers' generation in Germany and elsewhere from the 1960s to 
the 1990s: what lessons can be drawn from this experience for the arrival and the integration of refugees? Third, Germany and other EU member states get the historic opportunity to arrive in Europe in a more substantial and sustainable way. Although the societal and political development after 2015 may invite more sceptical or pessimistic analysis and prognosis, the 'refugee crisis' contains the great opportunity to refine the project of a European society in a globalized world. Finally, the challenges and opportunities of letting refugees and other social groups arrive are discussed by presenting different models of social integration and deepening the understanding of arrival (Chapter 7). Arriving as a concept in a broader perspective, as developed by Hannah Arendt, also means remembering and rooting (see Chapter 7, section 7.3). The new transnational social question invites us to arrive at the current state of the global world by taking over global responsibility. 